\title{
After Babel
}

Aspects of Language and Translation

\section{George Steiner}

There is 'translation' in every act of human speech, for to understand is to interpret. After Babel is the first attempt since the eighteenth century at a systematic investigation of the phenomenology and processes of translation, inside language and between languages. It is a demanding, thought-provoking book which goes to the very centre of man's relation to the word. $£ 8$

\section{Semantic Syntax}

\section{Edited by Pieter A. M. Seuren}

The aim of this collection of articles, some of which have not been published in English previously, is to provide an insight into certain live issues of linguistic theory which seem crucial to our understanding of the phenomenon 'human language'. Two problem areas have been singled out: the nature and grammatical status of lexical items, and the relation between linguistic structure and classical predicate calculus. Paper covers $£ 1.20$ Oxford Readings in Philosophy

\section{Oxford University Press}

\section{Explorations in the Ethnography of Speaking Edited by RICHARD BAUMAN and JOEL F. SHERZER}

The 'ethnography of speaking' has emerged only quite recently as a separate field of enquiry. It draws on linguistic, literary and anthropological techniques and interests, and brings them to bear on speaking as a theoretically and practically crucial aspect of human life, and on ethnography as a study of patterns and functions of speaking in societies. The studies in this volume span the entire globe-from Amazonian Indians to 17th-century Quakers, from the New Zealand Maori to American Blacks.

Hard covers $£ 9.00$ net

Now in paperback:

Paperback $£ 3.60$ net

\section{Semantics}

An Interdisciplinary Reader in Philosophy, Linguistics and Psychology Edited by DANNY D. STEINBERG and LEON A. JAKOBOVITS

A paperback edition of this successful book, first published in 1971.

Paperback $£ 2.95$ net

\section{CAMBRIDGE UNIVERSITY PRESS}




\section{Creole Drum}

\section{An Anthology of Creole Literature in Surinam}

Jan Voorhoeve and Ursy M. Lichtveld, editors

English translations by Vernie A. February

"The book is of very real scholarly importance for students of the African heritage in the Americas and for social historians, anthropologists, and linguists. The texts may well comprise the finest corpus ever assembled for any creole language in their variety of genres and themes and in the richness of their ethnographic and social content. Sranan is one of the least known, yet most often maligned, of all Afro-American languages. This book, in one fell swoop, introduces a whole new literature-a group of poems, songs, and stories that speak very much for themselves."-Richard Price \$12.50

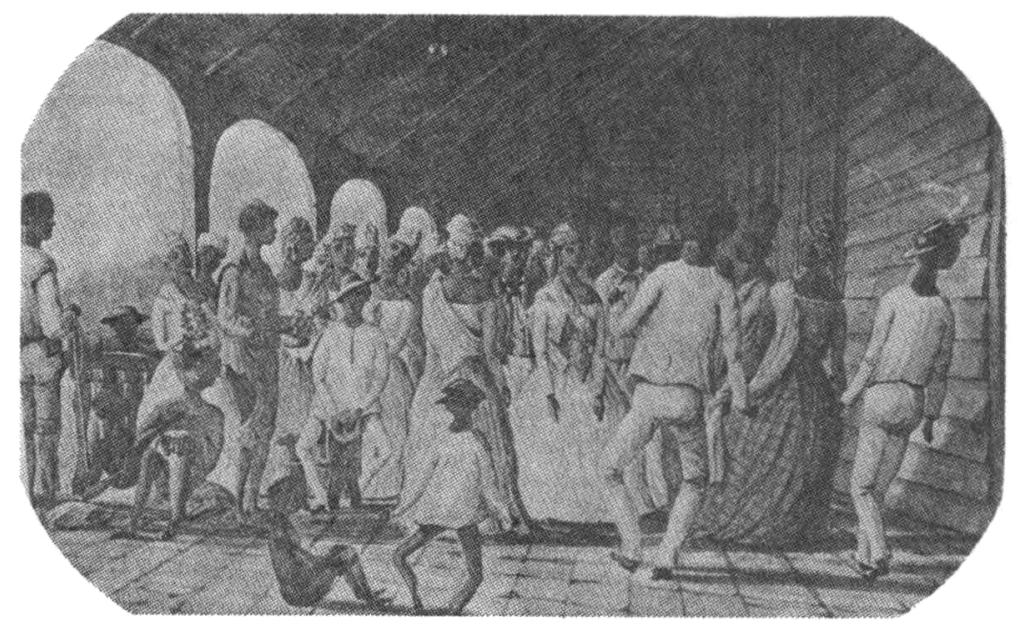

\section{Yale University Press New Haven and London}


Typescripts. The top copy of the typescript should be submitted and, if possible a second copy also. Contributions should be clearly typed on one side of the paper only using a conventional size of paper, preferably $\mathrm{A}_{4}$ (or 2 r.6 by 28 centimeters for those at work where $\mathrm{A}_{4}$ is not available). Authors should hold one copy for the correction of proofs. The title-page should include the title, author's name and affiliation, in that order, along with an abstract of the article. Areas of study to which the articles may be of interest should be listed at the end of the abstract.

Titles should be so worded that the first part may be used as a running headline (with a maximum length of 50 characters, including spaces). They should be typed on a separate sheet, together with the author's name and the address to which he wishes proofs to be sent.

Citations and forms of emphasis. Normally the Latin alphabet is to be used. Cited forms should be underlined to represent italicization in print. Translational 'meanings' should be placed within single quotation marks.

References are to be made in the text (and not in footnotes) by giving in brackets the name of the author and year of publication, and where relevant the page(s) referred to; e.g. (Whitney i $867: 45-53$ ). If the author's name is part of the text, the following form should be used: 'Whitney (1867: 48) maintained that .... When a work written by two or more authors is referred to, all names should be given in the first citation; e.g. (Weinreich, Labov \& Herzog I968): in subsequent citations the first name only should be given, with 'et al.' added; e.g. (Weinreich et al. 1968). When separate works are referred to in the same bracket, those by the same author should be separated by commas and those by different authors by semi-colons: e.g. (Whitney I 867; Firth 1935, 1957a). Initials should be used (after the author's name) only when it is necessary to distinguish between two or more authors of the same name, all of whom are referred to in the same article.

All works referred to should be listed at the end of the article, double-spaced and in alphabetical order. The titles of articles should so far as possible be abbreviated according to the conventions of the
Linguistic Bibliography of the Permanent International Committee of Linguists (CIPL).

Examples of references (note the use of punctuation marks within references):

Firth, J. R. (1957a). Ethnographic analysis and language with reference to Malinowski's views. In R. W. Firth (ed.), Man and culture: an evaluation of the work of Bronislaw Malinowski. London: Routledge and Kegan Paul. 93-Ir8.

- $(1957 b)$. A synopsis of linguistic theory, 1930-55. Studies in linguistic analysis (Special volume of the Philological Society). Oxford. I-33.

Sapir, E. (1929). The status of linguistics as a science. $\operatorname{Lg} . \mathbf{5}, 207-14$. (Reprinted in D. G. Mandelbaum (ed.). (I 939) Selected writings of Edward Sapir. Berkeley and Los Angeles: U. California P. I60-6.)

Book reviews. With the exception of the title-page, book reviews should be submitted in the same form as articles. The title-page should take the following form: Edwin Ardener (ed.), Linguistic and Social Anthropology. (ASA Monographs, ro.) London: Tavistock, I97I.

Reviewed by Clive Criper

Department of Linguistics

University of Edinburgh

There is no need to submit an abstract with a book review.

Proofs. First proofs only will be sent to the author (or his nominee), who will be expected to correct them and return them to the Editor, by airmail where appropriate, within ten days of receipt.

Separates. Fifty separates of both articles and review articles will be provided free of charge. Additional separates may be obtained at reasonable cost, provided that these are ordered before publication on the special form sent out with the proofs.

Submission of an article is taken to imply that it has not previously been published, or is not being considered for publication elsewhere. If an author is publishing a related article elsewhere, this fact should be stated.

Copyright. Contributors of accepted articles will be asked to assign their copyrights, on certain conditions, to Cambridge University Press, to help protect their material, particularly in the U.S.A. 
Lang. Soc. 4, I

\section{Language in Society}

Volume 4 Number I April 1975

Conversational devices and structures

J. D. SAPIR: Big and thin: Two Diola metalinguistic terms

M. C. GRAYSHON: Some aspects of social grammar: Features of one type of question in English and Yoruba

E. MISHLER: An exponential law of successive questioning

K. A. WATSON: Transferable communicative routines

REVIEWS

Directions in sociolinguistics

B. BERNSTEIN: Class, codes and control (Poole) 73

J. J. GU M PERZ: Language in social groups (Sack)

W. LABOV: Sociolinguistic patterns (Traugott)

A. SCHWEIZER: Problems in the sociology of language in contemporary American linguistics (Samarin and Kalmar)

\section{Other}

J. COOK-G UMPERZ: Social control and socialization (Erickson)

R. SHUY \& R. W. FASOLD (eds.): Language attitudes: current trends and prospects (Agheyisi)

SHORTER NOTICES

(C) Cambridge University Press 1975

CAMBRIDGE UNIVERSITY PRESS

Bentley House, 200 Euston Road, London NWI 2DB

32 East $57^{\text {th }}$ Street, New York, NY 10022

Single parts $£_{5.00}$ net in UK (US $\$ 15.00$ in USA and Canada) Annual subscription $\oint_{1} 12.00$ net in UK (US $\$ 36.00$ in USA and Canada) 